\title{
Media and Information Technology in Ten Years' Time: A Society of Control both from Above and Below, and from Outside and Inside
}

\author{
Jörg Becker \\ Komtech Solingen, Germany, joerg.becker@komtech.org
}

\begin{abstract}
In the process of continual change from the hand axe to the factory and now to industrial production 4.0, technology has had, and still has, two basically invariable functions: control and rationalisation. Each of these two terms is to be understood in a very comprehensive sense, in technical, engineering, commercial, legal, and social terms. This tenet also applies to television and to information technology. In my lecture, the terms "above" and "below" stand for a model of social stratification; they stand for capital and labour. The terms "outside" and "inside" stand for the external conditions of the class struggle from "above" and "below". The external conditions mean the social and the inside conditions mean the psychological environment. Both television and information technology rely on content and organisational forms that run from above to below (from top to bottom). Moreover, contrary to Gutenberg's invention of moving letters, today innovations in the media and IT fields no longer run from the bottom up, but only from the top down. While television conditions the individual from outside, users of social media internalise that same conditioning as liberation from constraints.
\end{abstract}

Acknowledgement: This text was presented as a lecture at the 5th ICTs and Society Conference "The Internet and Social Media at a Crossroads" that was part of the International Society for Information Studies' Information Society Summit in Vienna, Austria, June 4, 2015, session "The Critical Perspective: Empirical Findings and Theory".

Keywords: information society, control, media, information technology

Theodor W. Adorno, Max Horkheimer and George Orwell, all of them politically well reputed left-wing intellectuals each with his very own independent intellectual edifice, came to the same conclusions at the same time about German Fascism. The philosophical fragment Dialect of Enlightenment of 1944, the novel Animal Farm of 1945 and the novel 1984 of 1946/48 all deal with the same theme, namely, the totalitarian surveillance state from which there is no escape, in which those rebelling against the reign of violence, once they have been successful in their rebellion, impose a more brutal rule than their predecessors, in which the Ministry of Truth monitors the past, a state-imposed newspeak replaces everyday language, and the War Ministry is renamed the Peace Ministry. Here human barbarianism seems to be the civilizational consequence of an enlightenment that is always understood merely instrumentally.

But reality still always provides the best satires. Since Edward Snowden's revelations about the all-embracing surveillance practices by the NSA of all global electronic communications, democracy has ceased to exist. Where there is no longer a case-by-case review, where anticipation replaces the legal judgement of an established criminal act, where there is no longer an assumption of innocence, where no communicative private sphere exists anymore, and where courts decide in secret and without the possibility of appeal, then the state based on the rule of law is dead. To use the term surveillance democracy is to already play it down somewhat.

\section{Above and Below}

For about the past 150 years of industrial capitalism, it has been a societal inevitability of the development of productive forces that new technologies can no longer be differentiated ac- 
cording to a good or bad use of them. Günther Anders realized this as early as 1956, when he remarked about television that, "No mean is only a means". A new technology is no longer neutral, being already subject to the patterns of profit maximisation and instrumental exploitation in the process of their genesis. It always comes from above and is always used to stabilizing power. Things were different once upon a time, and Johannes Gutenberg is a good example of this.

His invention around 1450 of moving letters for printing books was not only technically innovative, but above all, socially innovative. It was an invention by the urban bourgeoisie in its struggle against church and aristocracy. Through the dissemination of the Bible in book form and through Martin Luther's translation of the Bible into German in 1520, these two bourgeois revolutionaries robbed church and aristocracy of their written, Latin monopoly over knowledge, and with that, of their hegemony over the interpretation of God and the world. It was a successful struggle from below against above by means of a new communication technology. Things have changed since.

When German radio broadcasting was born in 1923, it was state, centralist, and liable to charges-it went hand in hand with the prohibition to produce radio broadcasts by private people, especially against the Rote Funker movement; it was also a restriction of the technical features of their terminal devices. And the step from an Internet previously subsidised by the state and the military to a public infrastructure in 1994 ran parallel to the criminalisation of hackers, who only shortly before that had been lauded as computer pioneers.

Nothing is more suitable for illustrating the concept of state control of the social behaviour of its citizens as the history and organisation of television. German television was born as state television twice, firstly, on the occasion of the Fascist Olympic Games in Berlin in 1936 and again in 1952. It was kept firmly in the hands initially of the state and then of public administration until all the TV infrastructures-i.e., transmission, distribution, social conditioning an adaptation into the every day life of the viewers-were so well developed that in 1984 they could be given over to private companies to maximise their profits without those company having to pay a single cent for the thirty years of advance payments of public money.

Moreover, an apparently only technical aspect is of decisive importance for the birth of German television in 1952. It would have been possible at that point in time, and in purely technical terms, to opt for a technical implementation of Bertolt Brecht's political theory of radio in 1932, namely, as a two-way medium. It would have been technically possible in 1952 to develop the new medium of television not as a network with one broadcaster and many receivers, but as a network with a feedback channel allowing recipients to participate technically. Needless to say, such a concept could not appeal to the politically strong control concept of a centralised Adenauer state, which disseminated propaganda from above to below only, and had plans for both a new propaganda ministry and state television.

Since the privatisation of the German television landscape, in which, with a certain timelag, the public TV stations have adapted to the programming of private TV stations, television can be defined as the sell off of different target groups to the advertising industry. In this sales process, programme content is just the free lunch, and as the consumer goods industry transfers its advertising costs to the consumer products, the user thus pays indirectly a TV charge for the programmes of the private TV stations. So this economic model approximates to a licence to print money both for the private TV stations and for the consumer goods industry.

In the early $21^{\text {st }}$ century, socialisation in the industrial countries means above all media socialisation. The mass media, as socialisation agencies, make an essential contribution to the fact that during their social learning processes the members of society can fulfil all sorts of social norms and role expectations. Integration is a concept that can scarcely be separated from socialisation. The mass media are the most important agencies for an integration of social communication. Here the "entertaining" free lunch of television takes first place-in Germany, at an average of four hours of broadcasting time per day in 2014. Given the average life expectancy of 80 years in Germany, this correspondents to about ten years of life consuming TV 24 hours a day. 
The social control exerted by television is precarious in many ways. On the one hand, a socialisation shift form primary experiences to secondary, meaning media experiences, promotes an increase in alienation. On the other hand, the content of media programming turns out to be ethically questionable and dysfunctional in regard to a democratic public domain. As early as 1980, the so-called father of Latin American communication research, Luis Ramiro Beltrán, in his book Communicacion Dominada, outlined the following twelve elements as the basic norms in the what TV offered in most countries: individualism, elitism, racism, materialism, adventurism, conservatism, conformism, defeatism, belief in fate, fixation on authority, romanticism, and aggression. Sexism is surely a further element that can and has been added to these.

The great increase in TV channels since the early 1980s due to cable and satellite television has led to an intensification of these thirteen basic media offers, but not to a pluralisation of content and opinion. In that period of time, the number of TV channels in Germany increased from two public channels to 150 private television stations, and a sobering experience is that the increase in the number of TV channels has not led to a richer content, but to a multiplication of the same content. Noam Chomsky coined a linguistically apt and catchy term for the social function of television in the title of his film and book The Consensus Factory (1988/1994) and in the concept of consent without consent which he took over from the English sociologist Anthony Giddens.

Information control is particularly difficult to define when it takes place with the apparent agreement of those being controlled. It is here precisely that the idea of the control society which Gilles Deleuze outlined in his book Pourparlers (1990): those being controlled feel well under that control; they enjoy and internalise it. In the field of television, this internalised control can be seen clearly in the series Big Brother, which started in the Netherlands in 1999. In that series, for 24 hours 24 cameras registered the life of so-called volunteers in a closed apartment. At regular intervals the viewing public-by means of a telephone ballot and the Internet-forced one of the participants to leave the apartment and to end the game. Do the TV viewers control the game? What is the difference between players and viewers? Which of them is more cynical?

If up until the 1980s a social control by the mass media was a result, impact, and function of desired political action by state and government, this put an end to by the de-regulation of the mass media under the banner of neo-liberalism. The policy of de-regulation was, and still is, a self-decapitation of politics-a transfer of the mass media to the exclusive social control of the market.

The favourite argument that I am generalising inadmissibly with my deliberations, given that there is the one or two good TV programmes, overlooks two things. One, the exception still proves the general rule. Two, this argument fails to understand the role that culture has played for some time now for turbo-capitalism. In his book, The Transformation of Democracy (1967), Johannes Agnoli was able to clearly outline and analyse the fact that culture, especially where it is critical of the system, is only granted a playground because its critique is merely a cultural one, with no economic dimension. Where there is no systemic critique of turbo-capitalism, a repressive tolerance will allow many a critical cabaret show, many a politically cheeky song and many a Heute Show.

\section{Outside and Inside}

In view of the triple technological convergence of information technology with telecommunication and television, which, as a troika, have long since overtaken the automobile and chemical industries as a driving force in the economy, Gilles Deleuze's concept of the control society applies in two ways. Control from below and from within takes place more through mass television; control from above and from without takes place more through IT technologies.

The control of information by military and intelligence services is anything but a new phenomenon. In this context, the reason Oliver Cromwell gave for a state monopoly in 1657 is notorious: "The postal service will be one of the best means of uncovering and resisting dan- 
gerous and despicable attacks against the commonwealth." In other words, and drawing attention to the dialectics of freedom and force: the state promotes free communication so as to be better able to control it.

Since the NSA scandal, we know that current IT technologies have brought with them an incredible qualitative increase, particularly in the field of information control (which, by the way, few social scientists would have considered possible). I will briefly list just ten remarkable facts, connections, and processes that affect all policies to do with work, everyday life and capital:

- It is common knowledge, meantime, that the NSA controls the whole of telephone and the whole of Internet communication worldwide (both connection data and content). Currently, in Utah, the NSA is building the world's largest data centre for storing a quadrillion text pages so as to be able to register and store global electronic communication of a period of 100 years. Moreover, the NSA is working on a so-called quantum computer that can decipher all encryptions. It is of course contested if and when such quantum computers can be built. The Federal German Intelligence Service, BND, cooperates with the NSA at different levels.

- In the high frequency trading done on the financial markets, just a few milliseconds, sometimes even nano-seconds, decide on the financial success or failure of a money transaction. The international finance market is thus out of control.

- In the future Industry 4.0, the so-called Internet of things, information processing is already indispensable, resulting in a total tracking, i.e., a trail tracking of all movements, actions and services. This automated wave of industrialisation will drastically increase both the structural unemployment that already exists, as well as the productivity growth and the profits of enterprises. And 3D printings will confront us with changes in productivity and security, the impacts of which we can scarcely oversee due to their complexity.

- Wi-Vi, a radio device developed by the Massachusetts Institute of Technology, can observe through walls.

- The American chain of shops called Macy's with a special technology can recognise each client entering the shop by means of a corresponding App on his or her smart phone; it can follow that client around and link what it records with his or her user Internet behaviour. Marketing specialists call this consumer DNA.

- Supermarkets that use cameras with a software developed by the Denmans company can not only observe their clients, but also assess how they are thinking and feeling with seven so-called primary emotions: anger, derision, repulsion, anxiety, joy, sadness and surprise.

- By linking communication data with biometric data for face recognition, the state has the possibility of surveying its complete population.

- So that home appliances can communicate with one another and new markets be tapped thanks to the usage data gained, Google has bought up companies that produce smoke alarms and thermostats.

- By means of speech-commands, Amazon can enable its loudspeakers installed in private apartments to record all conversations taking place in those apartments.

- Amazon has taken out a patent on an algorithm that sends a package before anyone has ordered it. Linking the usage data of Amazon clients is heading, according to Amazon, in the direction of what it calls anticipatory dispatch.

These are just a few examples, but their social message is the same everywhere: legal concepts such as the right to informational self-determination guaranteed by the constitution, data protection, a private and intimate sphere, will become historical residual categories in a global neoliberal economy with less and less regulated free spaces for doing whatever. And anyone who thought the NSA scandal was a welcome occasion for making international relations more transparent and democratic was mistaken in many ways. 
Firstly digital capitalism illustrates the existing, still unchecked, global dominance of the US. Not only did Henry Kissinger, on a secret visit to China in 1970, agree with Deng Xiaoping on the construction of two US communications intercept stations in the Chinese province of Xinjiang which were active up until the 1990s-to give just one scarcely known example of the range of US American supremacy-US American Internet giants like Google, Microsoft, Amazon, Apple, IBM, General Electric, or Cisco dominate the global cyber world.

What is more, the network supplier Cisco is another highly interesting example of the intricate and contradictory US-Chinese cyber-relations. While the US State Department, in its ritualized annual report on the state of human rights, laments the violation of those human rights in the Chinese Internet, the US Cisco company sells the Chinese government the filter software for monitoring the political content on the Chinese Internet (with the cognizance of the US American secret services, needless to say).

Secondly, the NSA scandal is a welcome occasion for the Europeans, and especially the Germans, to expand its own digital infrastructure for eavesdropping, intercepting, and controlling. Currently a gigantic dynamism can be observed in the apparently competitive world between the USA and the EU. To put it cynically: the German Intelligence Service or BND is benefitting from Edward Snowden's revelations.

Thirdly and finally, the NSA scandal is also an occasion for serious concern, even resignation in that no treaty could successfully prompt the USA to end its global cyber controls through the NSA, for the simple reason that apart from the USA no other country would be technically in a position to be able to verify such an American termination of activities.

It is possible, however that these forms of external control are much less drastic in their social consequences than the different forms of self- and internal control. I would just like to list three of these:

- $\quad$ The structure and organisation of social media such as Facebook are characterised by the fact that they seem to rely on the voluntariness of their users. Like the lovemark philosophy of the Saatchi \& Saatchi advertising agency or the smiley philosophy of the US American advertising graphic artist Harvey Ball in the 1960s, here too it is a question of the maximum number of "followers" and "likes". Facebook users, deeply rooted in the so-called Californian ideology (a hippies' concept of freedom plus the high-tech industry's capital interests), voluntarily and continually disseminate hundreds of private and intimate data about their person throughout the digital universe. They are not worried by the fact that these data form the basis of digital marketing and control strategies of Facebook. However, refusal strategies towards Facebook come to nothing. The global attractiveness of Facebook is already so strong that a digital public sphere is only possible by participating in it. It goes without saying that the public sphere of Facebook differs from that of Jürgen Habermas. It is a private commercial public domain that functions according to the General Terms of Trade of the market-monopolist Facebook.

- Equally complicated is the "voluntariness" of the digital dissemination of health data by medical insurance companies. A user-the insurance branch calls him or her a self-optimiser- "voluntarily" measures his pulse with a body sensor, the number of steps taken daily, and other sporting activities. If he or she "voluntarily" transfers theses heath data to their medical insurance company, they are rewarded with a bonus and various prizes. In possession of these data, the insurance company can draw up individualised contribution strategies, thereby minimizing their costs and maximizing their profits. With these individualisation strategies, the insurance companies are destroying the solidarity principle of the insurance industry that has existed for a good 180 years.

- The fashion for selfies and the concomitant selfie-sticks is much more than a fashion given that as every fashion is embedded in the economic and social environment that give rise to it. Selfies reflect the typical narcissism of a helpless and aggrieved generation of young people who, in the world of the current turbo capitalism, are both uprooted and can also be flexibly deployed in any work place throughout the global 
economy. Narcissism here is not a morally condemned self-love orientated around the bourgeois norm of heterosexuality, but the expression of neoliberal isolation.

A larger framework is required to interpret such "voluntariness" and, in the old Marxist tradition, it must be established first and foremost that the principle of voluntariness does not apply in a capitalist market because it presupposes the structural equality of possession of the means of production and human work. That would be nonsense, and has never applied! Furthermore, from a pragmatic perspective, the structural unemployment that has existed for some times now rarely facilitates an everyday freedom to choose between several available jobs.

The reference to the Californian ideology is still useful here, as it involves an individualised hedonistic and unpolitical concept of freedom that recognizes no social feedback or social responsibility. To put it more drastically: this kind of "voluntariness" demands and promotes an atomised Ego that has to hire itself out as a sole entrepreneur on a neoliberal digital markets, needless to say, without a working contract, a tax card, a legal old-age pension insurance, without trade unions and without a works' council. In the boundlessness of the global digital market, "voluntariness" and "flexibility"-once very important and politically positive primary virtues in the social-democratic welfare state-have degenerated into a necessary commodity, to purely instrumental secondary virtues, without which no one can earn any money. Flexibility has meantime become the most important cultural asset in the current formation of capitalism - as the US-American sociologist Richard Sennett realised as early as 1998.

If in the following I still draw attention through the terms work and difference to moments of resistance to the control processes described, then I do so with recourse to Theodor W. Adorno. I adhere, with Adorno, to the term work because of the subject-object dialectics. As the possibility of individualisation in the non-identical is to be assumed, again with Adorno, there exists a dimension by itself, namely, that of difference and of diversity as a principle of socialisation. And, this time contrary to Adorno, who thought and argued in a hopelessly euro-centric way, this principle of a difference applies all the more against the backdrop of intercultural philosophies and of encounters with the cultures of Latin America, Africa, and Asia.

\section{Work}

Since the mid-1990s, social science has repeatedly failed when it came to analysing the organisation and structure of the global electronic digital network. In social sciences and in the uncritical publications that accompanied it, we meet those empty slogans about the infinite freedom of communication, the boundlessness of the exchange of ideas, unrestricted access to the whole body of humanity's knowledge and the hymn to clean, low-energy, purely ideal productive force, in keeping with the naïve motto: knowledge is the petroleum of our day! Only recently have colleagues been speaking, with total conviction and even seriously, about the "dematerialisation" of the media economy!

Such analyses are superficial, false, and highly ideological because they disregard the concrete working conditions of many millions of people employed worldwide in the production, dissemination, and the disposal of IT products and services. These people have to organise themselves very traditionally in trade unions in order to improve their working conditions.

I am thinking of the mine workers in Zambia, who toil under unbearable conditions mining the cobalt required for each and every PC, and of the people living close to those mines, who have to endure the effects of the polluted soil and drinking water. I am also thinking of the thousands and thousands of women who, in some customs-free zones in some developing country, produce computer chips in factories where the guidelines on the handling of poisonous solvents are not adhered to so that those women are exposed to a greater danger of cancer and a higher risk of miscarriages. I am thinking with horror and repulsion of the high suicide rates in the Foxconn company in Shenzhen in 2010, because the workers producing 
iPods for Apple were unable to bear the inhuman working conditions any longer. Then, I am also thinking of the children on the huge rubbish tips near Accra in Ghana, or near Manila on the Philippines, who have to make a living by gathering and sorting European and American computer refuse, work that, again, seriously damages the heath of those people because of the lead-polluted soil.

A fifth case I am thinking of is the many millions of women worldwide whose secretarial jobs were rationalized away as a result of the enormous impetus of PCs and digital networking. Now as outsourced electronic homeworkers, such women are caught between bringing up children and a badly-paid job at their private computer, with only a special-order contract and not a working contract, totally isolated socially, with neither colleagues nor a works' council.

Finally, I would like to mention the slave-like working conditions in the warehouses of Amazon, a concern that has been aggressively hostile towards trade unions since it was founded in 1994. At Amazon, on the basis of a false pay agreement with groups of wage squeezers, commodities are ordered in freezing cold warehouses, and the intellectual world of books shatters on the rocks of non-intellectual, dull sorting process done in piecework. While the Amazon employees in Germany are slowly organising themselves in trade unions, the company is already building new warehouses in Poland with even worse working conditions and even lower pay.

So that is the material basis, the concrete side of our glittering digital world! And now as then in what are in principle well-known social emergency situations and struggles, it is all about class struggle, solidarity, self-organisation, self-and co-determination, trade union and works council work, because that is the only way of ensuring a good and humane life beyond a totally neoliberal controlling state. Whereas reflection on the category of work necessarily leads to reflection on future alternatives, it is not so immediately obvious that this also applies to the category of diversity.

\section{Difference}

In 2005, when UNESCO passed its Convention on the Protection and Promotion of the Diversity of Cultural Expressions, this happened almost unilaterally, but against the vote of the US.

Why?

Diversity-particularly in the realm of words, languages, information, culture and knowledge-can become a hugely important source of resistance to the general homogenisation tendencies in culture and knowledge that are originating from the US.

First and foremost, there is the world of oral culture, which largely eschews and rejects the instrumental and commodity-like grip of capitalist modernism.

Then there is music and poetry, whose immediacy, whose simplicity of self-production and very specific local character make them only marketable to a certain extent, despite all modernism.

Thirdly, it should be remembered that interculturality always only works in a rudimentary way. Cultural "residues" remain endogenous, are not comprehensible to outsiders and therefore resist any kind of transfer, meaning also commercialisation.

It is in keeping with the peculiarities of what we call knowledge that is resists any systematic storage and so cannot be stacked and stored. By definition, all knowledge has fluidity, even though computer technology was created precisely to shatter this peculiarity so as to make knowledge scarce and thus be able to turn it into a saleable commodity. But that is only feasible within precise limits.

Fifthly, the old concept of a commons, i.e., the free use of a village meadow by the village dwellers, could undergo a realistic renaissance in globally networked free self-learning software.

Sixth, thanks to the different Internet applications and on the basis of swift communication with millions of recipients, it is possible to observe something like swarm intelligence, crowdfunding, crowdworking, shitstorms or electronic petitions with complaints, appeals for clem- 
ency and referenda. Here, exercising maximum caution and great scepticism, quantity could lead to quality.

On this sixth point, I am deliberately using the subjunctive form. On the theme of digital resistance, whenever reference is made, for example, to the proud figure of 1.1 million digital signatures against the two trade agreements TTIP and CETA, a warning should be issued against a technology-determined argumentation, irrespective of this civic success. After all, the digital opponent does not sleep and can produce equally impressive figures. All the approx. twenty so-called colourful revolutions that have taken place since about the year 2000, have worked successfully with prepaid mobile phones, flash mobs, Facebook, Twitter, YouTube, and the Internet, and more or less all those movements were financed to a significant degree by US institutions (Soros Foundation, National Endowment for Democracy, etc.). In other words, in such cases any emphatic reference to the fact that digital media are suitable as resistance media must be preceded by a basic discussion about how the political weights are divided between the leaders and the led in any one concrete situation.

\section{Forecast}

In this context, I would like to refer first to the Divine Comedy by the great $14^{\text {th }}$ century poet Dante Alighieri. In the $20^{\text {th }}$ Canto of the first Book, he simply despatches all diviners and prognosticators to Hell, where they may only walk with their heads turned backwards: See how he walks backwards, looks backwards, because he wanted to see too far forwards."

In other words: alongside need research, prognostics is one of the, methodically, most difficult fields of social science, economics and the anticipatory study of technology development. And often enough, many prognoses have, in retrospective, turned out repeatedly to be seriously wrong.

To date, prognostics takes the two following methodological approaches: the retrospective view is prolonged forwards either in a linear or non-linear way, or else parallels are drawn to previous situations in other countries. Although I am aware of their respective methodological shortcomings, I have nevertheless used both methods in this lecture.

For a social science debate about what will be in ten years' time, perhaps it would be better, much better, to use neither of these two methods, but instead to try something completely different. Would it not make much more sense for social scientists to conceive parameters for how a future society should look and how they would wish it to be, and then, in a second step, to consider which strategies and tools could be used to achieve the desire aims?

I would like to end my lecture by quoting from the German newspaper, the Frankfurter Allgemeine Zeitung, of 12 July 2013, just one month before the NSA scandal was revealed by Edward Snowden:

In order to protect highly secret information Russian security services are again relying more on typewriters. According to a report in the newspaper Isvestija the federal protection service FSO, one of the Russian secret services responsible for the safety of the president and the government, ordered 20 typewriters. Accordingly, particularly sensitive reports would only be archived on paper and not on electronic data storage devices so as to protect them from computer espionage.

Of course even producing information on a typewriter is not fully save. If someone bugs a machine, then texts can already be monitored during their production, such as in the NSA's GUNMAN project. And that's also possible with typewriters.

\section{About the Author}

Dr Jörg Becker is Honorary Professor of Political Science at Marburg University and Managing Director of the KomTech Institute for Communication and Technology Research in Germany. His work focuses on international and comparative media, and culture and technology policy. 